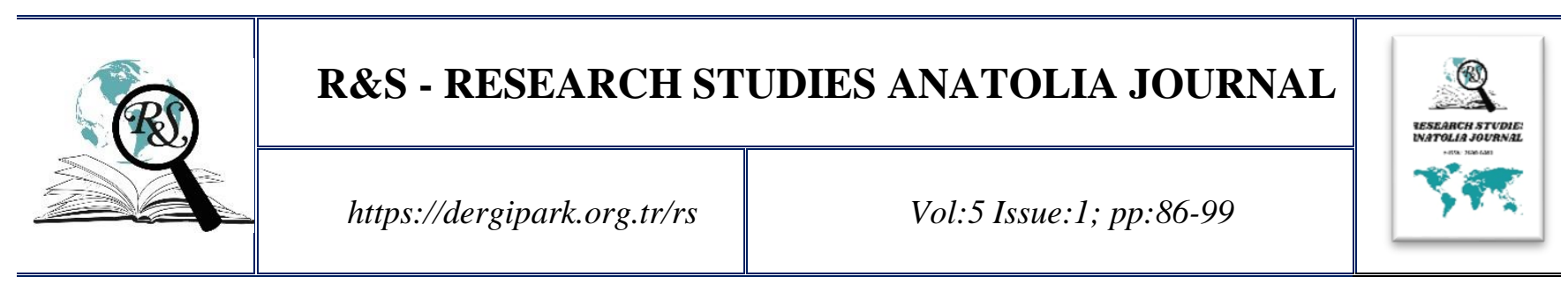

\title{
TÜKENMIŞLİK SENDROMU KONUSUNDA YAZILAN TEZLERİN KATEGORİK OLARAK İNCELENMESİ
}

The Categorical Investigation of Thesis on Burn Out Syndrome

\section{Burcu YíğìT}

Dr., Bağımsız Araştırmac1, brcygt@ hotmail.com İstanbul / TÜRKIYYE, https://orcid.org/0000-0002-2071-0099

Doi: https://doi.org/10.33723/rs.1037014

Yiğit, B., (2022), “Tükenmişlik sendromu konusunda yazılan tezlerin kategorik olarak incelenmesi”, $R \& S$-Research Studies Anatolia Journal, 5(1). 86-99.

Makale Türü: Araştırma Makalesi

Geliş Tarihi/ Arrived Date: 15.12 .2021

Kabul Tarihi / Accepted Date: 25.01.2022

Yayınlanma Tarihi / Published Date: 31.01.2022 


\title{
ÖZ
}

$\mathrm{Bu}$ çalışmanın amacı, pek çok bilim dalına çalışma konusu olan ve pek çok bilim dalının odağında olan tükenmişlik sendromu konusunda yazılan tezlerin kategorik olarak incelenmesidir. Bu kapsamda, tükenmişlik sendromu konusunda Türkiye'de yazılmış olan erişime açık 140 teze erişilmiştir. Bu tezler, içerik analizi ile incelenmiştir. Yapılan içerik analizinde, tezlerin yayım yılları, üniversite isimleri, anabilim dalları, dilleri, türleri, enstitüler, danışman unvanları, tezlerdeki değişken sayısına göre sınıflandırma yapılmıştır. Elde edilen sonuçlara göre, en çok tezin 2019 yılında yayımlandığı; tezlerin en çok Beykent Üniversitesi'nde yazıldığı, anabilim dalı olarak İşletme Anabilim Dalı; tez dili olarak Türkçe, tez türü olarak yüksek lisans; enstitü bazında Sosyal Bilimler Enstitüsü; tez danışmanı unvanına göre Dr. Öğretim Üyesinin en çok olduğu; değişken sayısı olarak en çok iki değişkenli çalışıldığ

Anahtar Kelimeler: Tükenmişlik Sendromu, Tükenmişlik, İçerik Analizi

\begin{abstract}
The aim of this study is to examine the theses written on burnout syndrome categorically, which is the subject of study in many disciplines and the focus of many disciplines. In this context, it was reached 140 open access theses written in Turkey on burnout syndrome. These theses were evaluated by content analysis. In the content analysis, the theses were classified according to the publication years, university names, departments, theses' languages, thesis types, institutes, thesis advisor titles, the number of variables in the theses. According to the results obtained, it has revealed that theses were mostly published in 2019; in Beykent University; in Business Department; Turkish as thesis language; master's degree as thesis type; Institute of Social Sciences on the basis of institute; Assistant Professor as the title of the thesis advisor; mostly with two variables.
\end{abstract}

Keywords: Burn Out Syndrome, Burn-Out, Content Analysis 


\section{Gİiș}

Pek çok farklı bilim dalında çalışılan, iş yaşamında gün geçtikçe önem kazanan kavramlardan bir tanesi tükenmişlik sendromudur. Günümüzde giderek artan bir problem haline gelmektedir (Leitao vd., 2021: 4). Son bir buçuk yıldır ülkemizi ve Dünyayı saran COVID-19 süreci ile birlikte, tükenmişlik sendromu da giderek artış göstermiştir.

Tükenmişlik sendromu ilk olarak 1974 yılında Freudenberger tarafından ele alınmıştır (Leitao vd., 2021: 4). Daha sonrasında ise, 1981 yılında Maslach kavramı ele almış ve ölçek geliştirmiştir. Bunun yanı sıra Maslach kavramı, iş yerinde kronik stresin sonucu olarak tükenmişlik sendromunu tanımlamıştır (Weber ve Jaekel-Reinhard, 2000: 512).

Tükenmişlik sendromu, örgütsel verimliliği, kişilerin fiziksel ve psikolojik sağlı̆̆ını olumsuz etkileyen, işe bağlı stres ve küresel bir kaygıdır (Carod-Artal ve Vazquez-Cabrera, 2013: 15). Dünya Sağlık Örgütü tükenmişlik sendromunu iş yerinde yönetilemeyen, kronik stresin sonucu olarak tanımlamaktadır. Tükenmişlik sendromu literatürde endişe (kaygı), depresyon, düşük tatmin ve bakım kalitesi ile ilişkilendirilmektedir (Magnavita vd., 2021: 2). Maslach vd., tükenmişlik sendromunu depresyondan farklı olarak iş yaşamında görülen duyarsızlaşma, duygusal tükenme (yorulma), kişisel başarıda düşme hissi olarak üç kategoride ele almıştır (Embriaco vd., 2007: 483).

Tükenmişlik sendromunun klinik semptomları yorgunluk, baş ağrısı, yeme bozukluğu, uyku sorunları, mide-bağırsak rahatsızlıkları, duygusal istikrarsızlık, diğer kişilere karşı katılıktır (Poncet vd., 2007: 698). Fiziksel yorgunluğa ek olarak, tükenmişlik sendromu kişilere karş1 pozitif duygular ve sempatiden yoksun davranışlarda bulunma, duygusal yorgunluk ile bağdaştırılmaktadır (Maslach ve Pines, 1977: 101).

Tükenmişlik sendromuna ilişkin çalışmaların pek çoğu sağlık sektörüne aittir (Chirico vd., 2021: 118). Sağlıcçıların kariyerlerinin her döneminde yaşayabileceği bir sendromdur (Bridgeman vd., 2017: 576). 
$\mathrm{Bu}$ çalışma, ülkemizdeki tükenmişlik sendromunun durumunun değerlendirilebilmesi amacıyla yapılmış ve erişime açık 140 tez çalışmaya dahil edilmiştir. Tezler içerik analizi ile değerlendirilmiştir. Tezlerin yayım yılları, üniversite isimleri, anabilim dalları, dilleri, türleri, enstitüler, danışman unvanları, tezlerdeki değişken sayısına göre sınıflandırma yapılmıştır.

\section{TÜKENMIŞLIK SENDROMU}

Pek çok farklı disiplinin odağında olan konulardan biri tükenmişlik sendromudur. İlk kez kavramı 1974 yılında Freudenberger ele almıştır (Rodrigues vd., 2018: 2; Leitao vd., 2021: 4). Freudenberger çalışmasında (1975) tükenmişlik sendromunu başarısızlık, yıpranma, enerji, güç ve kaynakların kişiyi yorması, yıpratması olarak tanımlamıştır (Freudenberger, 1975: 73). Tükenmişlik sendromu kişilerde başarısızlık duygusu, enerji ve güç kaybı, yıpranmışlık hissine sebep olmaktadır.

Tükenmişlik sendromunu yaşayanlarda konsantrasyon eksikliği, odaklanma sorunu, baş ağrısı, uyku bozukluğu, yorgunluk hissi, endişe duyma hali görülmektedir (Gil-Calderon vd., 2021: 2). Tükenmişlik sendromu yaşayan kişiler yaşantı ve başarılarından memnun ve mutlu değillerdir (Akkoç vd., 2020: 3). Bunlara ek olarak, kişilerin yaşam kalitesini düşürmekte, fiziksel sağlığını da bozmaktadır (Afonso vd., 2021: 683). Tükenmişlik sendromu fiziksel yorgunluğun yanı sıra, kişilerin duygusal yorgunluk hissi yaşamaları, kişinin iş ile ilgili sempatik ve pozitif duygu, düşüncelerden uzak olmasıdır (Maslach ve Pines, 1977: 101). Tükenmişlik sendromu literatürde duygusal tükenme, duyarsızlaşma ve kronik iş stresinin neden olduğu kişisel başarıda azalmanın kombinasyonu olarak değerlendirilmektedir (Bianchi vd., 2015: 1).

Kronik ve devam eden yorgunluk, psikiyatrik ve psikosomatik ve sosyal bozulmalar, agresiflik, ilgi ve konsantrasyonda eksilme, endişe, depresif ruh hali, kalp, mide ve bağırsak rahatsızlıkları tükenmişlik sendromunun belirtileri arasında yer almaktadır (Weber ve JaekelReinhard, 2000: 514). Bunun yanı sıra, tükenmişlik sendromuna yakalanan kişiler uyku 
bozuklukları, kronik ağrı sendromları, mide-kalp rahatsızlıkları yaşarlar (Bauer vd., 2003: 213).

Tükenmişlik ile birlikte kişisel başarıdaki azalma kişinin görev performansını düşürmekte, kişide mutsuzluk ve tatminsizlik yaratır (Montero-Marin vd., 2009: 1). Aynı zamanda kişilerde ciddi psikolojik ve fiziksel sağlık problemlerine sebep olmaktadır (Rodrigues vd., 2018: 2). Bu durum, kişinin verimliliğini de olumsuz etkilemektedir (Leiter, 1992: 110). Tükenmişlik yaşayan kişilerin hem psikolojik hem de fiziksel sağlıkları bozulmaktadır. Psikolojik sağlığın yanı sıra, pek çok fiziksel rahatsızlığa sebep olmaktadır. Bu durumun sonucunda kişiler gerek bireysel, gerekse kurumsal düzeyde etkilenmektedir. Kişiler ve kurumlarda olumsuz ve yıkıcı sonuçlara yol açmaktadır.

\section{ARASTTIRMANIN AMACI, ÖNEMI VE YÖNTEMI}

Bu çalışmada, tükenmiş sendromu alanında Türkiye' deki tezlerin genel bir profilinin ortaya konması hedeflenmiştir. Buna yönelik olarak Yükseköğretim Kurulu Ulusal Tez Merkezi'ndeki tükenmişlik sendromu konusunda yazılan tezler içerik analizi yöntemi ile değerlendirilmiştir. İçerik analizi, sistematik, objektif olan bir nitel araştırma türüdür. Aynı zamanda içerik analizinde kategoriler oluşturulmaktadır (Elo ve Kyngas, 2007: 108). Buna ek olarak içerik analizinde mevcut durumu değiştirmeye kalkmadan, hali hazırdaki mevcut haliyle betimlenmesi hedeflenmektedir (Bayram ve Yaylı, 2009: 359). YÖK Ulusal Tez Merkezi’nde toplamda 141 tez bulunmaktadır. 1 tez erişime kapalı olduğundan dolayı 140 tez çalışmaya dahil edilmiştir. Anahtar kelime olarak "tükenmişlik sendromu” yazılmış ve kategoriler oluşturulmuştur. Giderek günümüz iş dünyasında önem kazanmaya devam eden tükenmişlik sendromu kavramına yönelik olarak yapılan bu kategorik inceleme, gelecekte çalışma yapacak araştırmacılara 1şık tutacak, yol gösterici ve destek olacaktır. 


\section{BULGULAR}

Tablo 1'de tezlerin yıllara göre dağılımları verilmiştir. Tükenmişlik sendromu konusunda en çok tezin 2019 yılında ( $\mathrm{f}=30$ ) yazıldığı görülmüştür. Bunu sırasıyla 2018 ( $\mathrm{f}=17)$ ve 2017 (f=15) yılları izlemektedir. Tezlerin yıllara göre dağılımları gözden geçirildiğinde, 2014 yılı ve sonrasında yazılan tez sayısında artış olduğu dikkat çekmektedir.

Tablo 1. Tezin Y1llara Göre Dağılımları

\begin{tabular}{|c|c|}
\hline Tezlerin Yayımlandığı Yıllar & Siklık \\
\hline 2021 & 1 \\
\hline 2020 & 9 \\
\hline 2019 & 30 \\
\hline 2018 & 17 \\
\hline 2017 & 15 \\
\hline 2016 & 10 \\
\hline 2015 & 10 \\
\hline 2014 & 10 \\
\hline 2013 & 7 \\
\hline 2012 & 5 \\
\hline 2011 & 4 \\
\hline 2010 & 9 \\
\hline 2009 & 2 \\
\hline 2008 & 1 \\
\hline 2007 & 5 \\
\hline 2006 & 3 \\
\hline 2005 & - \\
\hline 2004 & 1 \\
\hline 2003 & - \\
\hline 2002 & - \\
\hline 2001 & - \\
\hline 2000 & - \\
\hline 1999 & - \\
\hline 1998 & 1 \\
\hline Total & 140 \\
\hline
\end{tabular}

Tablo 2'de görüldüğü üzere, üniversite isimlerine göre en çok tez Beykent Üniversitesi'nde yazılmıştır. Beykent Üniversitesi’ni İstanbul Üniversitesi izlemiştir.

Tablo 2. Tezlerin Üniversite İsimlerine Göre Dağılımları

\begin{tabular}{|l|c|}
\hline Tezlerin Yazıldığı Üniversite İsimleri & Sıklık \\
\hline Beykent Üniversitesi & 16 \\
\hline İstanbul Üniversitesi & 7 \\
\hline Dokuz Eylül Üniversitesi & 6 \\
\hline Dumlupınar Üniversitesi & 6 \\
\hline Marmara Üniversitesi & 6 \\
\hline Bahçeşehir Üniversitesi & 5 \\
\hline Üsküdar Üniversitesi & 5 \\
\hline
\end{tabular}




\begin{tabular}{|c|c|}
\hline Hacettepe Üniversitesi & 4 \\
\hline Pamukkale Üniversitesi & 4 \\
\hline İnönü Üniversitesi & 4 \\
\hline Dicle Üniversitesi & 4 \\
\hline İstanbul Okan Üniversitesi & 4 \\
\hline Niğde Üniversitesi & 3 \\
\hline Selçuk Üniversitesi & 3 \\
\hline Trakya Üniversitesi & 3 \\
\hline Gazi Üniversitesi & 2 \\
\hline Adıyaman Üniversitesi & 2 \\
\hline Maltepe Üniversitesi & 2 \\
\hline Sağlık Bilimleri Üniversitesi & 2 \\
\hline İstanbul Aydın Üniversitesi & 2 \\
\hline Kocaeli Üniversitesi & 2 \\
\hline Munzur Üniversitesi & 2 \\
\hline İstanbul Gelişim Üniversitesi & 2 \\
\hline Çukurova Üniversitesi & 2 \\
\hline Ankara Üniversitesi & 2 \\
\hline Anadolu Üniversitesi & 2 \\
\hline Kafkas Üniversitesi & 2 \\
\hline Adnan Menderes Üniversitesi & 2 \\
\hline Gümüşhane Üniversitesi & 1 \\
\hline Kahramanmaraş Sütçü İmam Üniversitesi & 1 \\
\hline Gaziosmanpaşa Üniversitesi & 1 \\
\hline Orta Doğu Teknik Üniversitesi & 1 \\
\hline Çanakkale On Sekiz Mart Üniversitesi & 1 \\
\hline Kütahya Sağlık Bilimleri Üniversitesi & 1 \\
\hline Ağrı İbrahim Çeçen Üniversitesi & 1 \\
\hline Türk Hava Kurumu Üniversitesi & 1 \\
\hline Süleyman Demirel Üniversitesi & 1 \\
\hline Sivas Cumhuriyet Üniversitesi & 1 \\
\hline Kütahya Dumlupınar Üniversitesi & 1 \\
\hline İstanbul Sabahattin Zaim Üniversitesi & 1 \\
\hline İzmir Katip Çelebi Üniversitesi & 1 \\
\hline Tekirdağ Namık Kemal Üniversitesi & 1 \\
\hline Avrasya Üniversitesi & 1 \\
\hline Balıkesir Üniversitesi & 1 \\
\hline Erzincan Binali Yıldırım Üniversitesi & 1 \\
\hline Ankara Yıldırım Beyazıt Üniversitesi & 1 \\
\hline Niğde Ömer Halisdemir Üniversitesi & 1 \\
\hline Toros Üniversitesi & 1 \\
\hline Gaziantep Üniversitesi & 1 \\
\hline İstanbul Ticaret Üniversitesi & 1 \\
\hline Akdeniz Üniversitesi & 1 \\
\hline Yeditepe Üniversitesi & 1 \\
\hline Atılım Üniversitesi & 1 \\
\hline Abant İzzet Baysal Üniversitesi & 1 \\
\hline Kırıkkale Üniversitesi & 1 \\
\hline Haliç Üniversitesi & 1 \\
\hline Mersin Üniversitesi & 1 \\
\hline Sağlık Bakanlığ1 & 1 \\
\hline Ege Üniversitesi & 1 \\
\hline Sakarya Üniversitesi & 1 \\
\hline Başkent Üniversitesi & 1 \\
\hline Yıldız Teknik Üniversitesi & 1 \\
\hline Total & 140 \\
\hline
\end{tabular}


Tezlerin anabilim dallarına göre dağılımları tablosu incelendiğinde, en çok İşletme Anabilim Dalı'nda tez çalışıldığı tespit edilmiştir (Tablo 3). İşletme Anabilim Dalı sonrasında bu sırayı İşletme Yönetimi Anabilim Dalı izlemektedir.

Tablo 3. Tezlerin Anabilim Dallarına Göre Dağılımları

\begin{tabular}{|c|c|}
\hline Tezlerdeki Anabilim Dalları & Sıklık \\
\hline İşletme Anabilim Dalı & 49 \\
\hline İşletme Yönetimi Anabilim Dalı & 11 \\
\hline Aile Hekimliği Anabilim Dalı & 6 \\
\hline Psikoloji Anabilim Dalı & 5 \\
\hline Halk Sağlığ 1 Anabilim Dalı & 5 \\
\hline Anesteziyoloji ve Reanimasyon Anabilim Dalı & 5 \\
\hline Klinik Psikoloji Anabilim Dalı & 4 \\
\hline Turizm İşletmeciliği Anabilim Dalı & 4 \\
\hline Acil Tıp Anabilim Dalı & 3 \\
\hline Psikiyatri Anabilim Dalı & 3 \\
\hline Sağlık Yönetimi Anabilim Dalı & 3 \\
\hline Eğitim Bilimleri Anabilim Dalı & 2 \\
\hline Hemşirelik Anabilim Dalı & 2 \\
\hline Afet Yönetimi Anabilim Dalı & 1 \\
\hline Kamu Yönetimi Anabilim Dalı & 1 \\
\hline Ruh Sağlığı ve Hastalıkları Anabilim Dalı & 1 \\
\hline Yabancı Diller Eğitimi Anabilim Dalı & 1 \\
\hline Tıp Eğitimi ve Bilişim Anabilim Dalı & 1 \\
\hline İngiliz Dili Eğitimi Anabilim Dalı & 1 \\
\hline Sanat Yönetimi Anabilim Dalı & 1 \\
\hline İş Sağlığı ve Güvenliği Anabilim Dalı & 1 \\
\hline Aile Danışmanlığg Anabilim Dalı & 1 \\
\hline Spor Yönetimi Anabilim Dalı & 1 \\
\hline Havacılık Anabilim Dalı & 1 \\
\hline İç Hastalıkları Anabilim Dalı & 1 \\
\hline Yönetim ve Organizasyon Anabilim Dalı & 1 \\
\hline $\begin{array}{l}\text { Sağlık Kurumları İşletmeciliği ve Yöneticiliği } \\
\text { Anabilim Dalı }\end{array}$ & 1 \\
\hline Uygulamalı Psikoloji Anabilim Dalı & 1 \\
\hline İş Güvenliği ve Sağlığı Anabilim Dalı & 1 \\
\hline Uluslararası Lojistik Anabilim Dalı & 1 \\
\hline Fizyoterapi ve Rehabilitasyon Anabilim Dalı & 1 \\
\hline Genel cerrahi Anabilim Dalı & 1 \\
\hline Göğüs Hastalıkları Anabilim Dalı & 1 \\
\hline Çalışma Ekonomisi ve Endüstri İlişkileri & 1 \\
\hline İnsan Kaynakları Anabilim Dalı & 1 \\
\hline Sosyal Hizmet Anabilim Dalı & 1 \\
\hline Turizm İşletmeciliği ve Otelcilik Anabilim Dalı & 1 \\
\hline Eğitim Yönetimi ve Denetimi Anabilim Dalı & 1 \\
\hline Sivil Havacılık Yönetimi Anabilim Dalı & 1 \\
\hline Halkla İlişkiler ve Tanıtım Anabilim Dalı & 1 \\
\hline Müzik Eğitimi Anabilim Dalı & 1 \\
\hline $\begin{array}{l}\text { Ortaöğretim Fen ve Matematik Alanları Eğitimi } \\
\text { Anabilim Dalı }\end{array}$ & 1 \\
\hline Büro Yönetimi Eğitimi Anabilim Dalı & 1 \\
\hline İletişim Tasarımı ve Yönetimi Anabilim Dalı & 1 \\
\hline Çocuk Sağlığı ve Hastalıkları Anabilim Dalı & 1 \\
\hline
\end{tabular}




\begin{tabular}{|l|c|}
\hline Sosyal Bilimler Anabilim Dalı & 1 \\
\hline Preventif Onkoloji Anabilim Dalı & 1 \\
\hline $\begin{array}{l}\text { İnsan Kaynakları Yönetimi ve Kariyer } \\
\text { Danışmanlığı Anabilim Dalı }\end{array}$ & 1 \\
\hline Çalışma Ekonomisi Anabilim Dalı & 1 \\
\hline Toplam Kalite Yönetimi Anabilim Dalı & 1 \\
\hline Eğitim Programları ve Öğretimi Anabilim Dalı & 1 \\
\hline Total & $\mathbf{1 4 0}$ \\
\hline
\end{tabular}

Tablo 4 incelendiğinde, tezlerin yazım dillerine göre dağılımları bulunmaktadır. Türkçe dilinde yazılan tezlerin, İngilizce dilindeki tezlere göre oldukça fazla olduğu dikkat çekmektedir.

Tablo 4. Tezlerin Yazıldığı Dile Göre Dağılımları

\begin{tabular}{|c|c|}
\hline Tezlerin Yazıldığı Dile Göre Dağılımlar & Sıklık \\
\hline Türkçe & 137 \\
\hline İngilizce & 3 \\
\hline Total & 140 \\
\hline
\end{tabular}

Tablo 5'te tezlerin türlerine yer verilmiştir. Yoğunluğun yüksek lisans tezlerinde olduğu göze çarpmaktadır. Sonrasında bu sırayı tıpta uzmanlık tezleri izlemektedir.

Tablo 5. Tezlerin Türlerine Göre Dağılımları

\begin{tabular}{|l|c|}
\hline Tezlerin Türleri & Sıklık \\
\hline Yüksek Lisans & 114 \\
\hline Tipta Uzmanlık & 24 \\
\hline Doktora & 2 \\
\hline \multicolumn{2}{c|}{ Total } \\
\hline
\end{tabular}

Tezlerin enstitü bazında dağılımlarına bakıldığında, en çok Sosyal Bilimler Enstitüsü’nde tezin olduğu gözlemlenmiştir (Tablo 6). Bu sırayı sırasıyla Tıp Fakültesi ve Sağlık Bilimler Enstitüsü takip etmektedir.

Tablo 6. Tezlerin Enstitülere Göre Dağılımları

\begin{tabular}{|l|c|}
\hline \multicolumn{1}{|c|}{ Tezlerin Yazıldı̆̆ı Enstitüler } & Sıklık \\
\hline Sosyal Bilimler Enstitüsü & 90 \\
\hline Tıp Fakültesi & 21 \\
\hline Sağlık Bilimleri Enstitüsü & 15 \\
\hline Eğitim Bilimleri Enstitüsü & 5 \\
\hline Eğitim Araştırma Hastanesi & 4 \\
\hline Lisansüstü Eğitim Enstitüsü & 3 \\
\hline Fen bilimleri Enstitüsü & 1 \\
\hline
\end{tabular}




\begin{tabular}{|c|c|}
\hline Adli Tip Enstitüsü & 1 \\
\hline \multicolumn{1}{|c|}{ Total } & $\mathbf{1 4 0}$ \\
\hline
\end{tabular}

Tablo 7'de tez danışmanlarının unvanlarına göre dağılımlar verilmiştir. Tablo incelendiğinde, tez danışman unvanlarının sayılarının birbirine yakın olduğu görülmüştür.

Tablo 7. Tezlerin Danışman Unvanlarına Göre Dağılımları

\begin{tabular}{|l|c|}
\hline \multicolumn{1}{|c|}{ Tez Danışmanlarının Unvanları } & Sıklık \\
\hline Prof. Dr. & 49 \\
\hline Doç. Dr. & 40 \\
\hline Dr. Öğretim Üyesi & 51 \\
\hline \multicolumn{2}{|c|}{ Total } \\
\hline
\end{tabular}

Tezlerde çalışılan değişken sayısına göre dağılımlar gözden geçirildiğinde, en çok iki değişkenli çalışılan tezlerin mevcut olduğu görülmüştür (Tablo 8). Daha sonra ise tek değişkenli çalışmaların sayıca çok olması dikkat çekmektedir.

Tablo 8. Tezlerde Çalışılan Değişken Sayısına Göre Dağılımlar

\begin{tabular}{|l|c|}
\hline Tezlerde Çalışılan Değişken Sayısı & Sıklık \\
\hline Tek Değişken & 48 \\
\hline İki Değişken & 67 \\
\hline Üç Değişken & 20 \\
\hline Dört ve Üzeri Değişken & 5 \\
\hline Total & $\mathbf{1 4 0}$ \\
\hline
\end{tabular}

\section{SONUÇ VE TARTIŞMA}

Tarihsel geçmişi 1970'li yıllara dayanan tükenmişlik sendromu olgusu günümüz iş yaşamının gerçeği ve kaçınılmazıdır. Bunun yanı sıra, tükenmişlik sendromu günümüzde bir sorun ve problem olarak karşımıza çıkmaktadır. Ülkemizde son yıllarda yazılan tez sayısı artış göstermiştir. Bu çalışmada YÖK Ulusal Tez Merkezi'ndeki tezlerin kategorik olarak incelenmesi hedeflenmiştir.

Elde edilen sonuçlara göre, tükenmişlik sendromu konusunda en çok tez 2019 y1lında ( $\mathrm{f}=30)$ karşımıza çıkmaktadır. Tezlerin yıllara göre dağılımlarına bakıldığında, 2014 yılı ve sonrasında yazılan tez sayısında artış dikkat çekmektedir. Tükenmişlik sendromuna ait tezlerin en fazla yapılmış olduğu yılın 2019 olması ülkemizde konuya ait duyarlılık, farkındalık ve konuya 
verilen önemin pik yaptığı zaman olarak değerlendirilmiştir. Kanımızca temel neden konuya olan ilgi ve önem, giderek yaşantımızda her alanda yer alan tükenmişlik sendromunun ta kendisidir.

Üniversite isimlerine göre incelendiğinde, en çok tezin Beykent Üniversitesi’nde ( $f=16)$ yazıldığı ortaya konmuştur. Beykent Üniversitesi'nden sonra en çok tez İstanbul Üniversitesi'nde ( $\mathrm{f}=7$ ) yazılmıştır. Konunun en çok Beykent Üniversitesi'nde araştırılma nedeninin akademisyen kadrosunun konuya olan ilgisinden kaynaklandığ1 düşünülmüştür. İstanbul genelinde bulunan üniversitelerde konunun ele alınması ise bir metropolün yarattığı özel güçlükler nedeniyle tükenmişlik sendromuna olan ilginin fazlalığı şeklinde yorumlanmıştır.

Anabilim dalı bazında değerlendirildiğinde, pek çok anabilim dalının tükenmişlik sendromu konusuna ilgi duyduğu belirlenmiştir. En çok İşletme Anabilim Dalı'nda (f=49) konunun çalışıldığı ortaya konmuştur. İşletme Anabilim Dalı sonrasında bu sırayı İşletme Yönetimi Anabilim Dalı ( $\mathrm{f}=11$ ) takip etmektedir. Tezlerin en fazla İşletme Anabilim Dalı ve ardından İşletme Yönetimi Ana Bilim Dalı'nda yapılmış olması hayatın her alanında etkin olabilecek tükenmişlik sendromu konusuna en çok bu alanların odaklandığını düşündürmektedir.

Tezlerin yazım dillerine göre dağılımları değerlendirildiğinde, Türkçe dilindeki tezler ( $f=137)$ çoğunluktadır. Buradan hareketle, tez öğrencilerinin anadillerinde tez yazmayı tercih ettikleri ya da ilgili olan okulların yönetmelikleri gereği olduğu yorumu yapılabilir.

Tezlerin türlerine göre incelendiğinde, tezler yüksek lisans, tıpta uzmanlık ve doktora tezlerinden oluşmaktadır. Yoğunluğun yüksek lisans tezlerinde $(\mathrm{f}=114)$ olduğu göze çarpmaktadır. Sonrasında bu sırayı tıpta uzmanlık tezleri (f=24) izlemektedir. Tükenmişlik sendromuna ilişkin tezlerin tıpta uzmanlık tezlerinde (Psikiyatri bölümü) de tercih edildiği dikkat çekmektedir. 
Enstitülere göre dağılımlar değerlendirildiğinde, en çok Sosyal Bilimler Enstitüsü’nde (f=90) tezin olduğu gözlemlenmiştir. Bu sırayı sırasıyla Tıp Fakültesi ( $\mathrm{f}=21)$ ve Sağlık Bilimler Enstitüsü (f=15) takip etmektedir. İlgili konu Sosyal bilimlerin odak alanı olmasına karşılık, Tıp Fakültesi ve sağlık alanında da konuya ilginin fazla olduğu görülmüsştür.

Tez danışmanlarının unvanlarına göre dağılımları gözden geçirildiğinde, sayıların birbirine yakın olduğu görülmüştür. Tez öğrencileri en çok Dr. Öğretim Üyesi unvanlı danışmanları ( $\mathrm{f}=51)$ tercih etmişlerdir. Tez danışmanlarının unvanlarına göre değerlendirildiğinde, sayıların birbirine yakın oluşu akademisyenlerin tüm kıdemlerde konuya ilgisinin olduğunu göstermiştir.

Çalışılan değişken sayısına göre dağılımlara bakıldığında, en çok iki değişkenli ( $f=67)$ çalışılan tezlerin mevcut olduğu görülmüştür. Daha sonra ise tek değişkenli ( $\mathrm{f}=48)$ çalışmaların sayıca çok olduğu dikkat çekmektedir. Tez öğrencileri tezlerinde daha çok ikili ve tekli değişkenli çalışmayı tercih etmişlerdir.

Bu çalışmadaki kategorik incelemeler 1şığında, günümüzdeki COVID-19 sürecini de göz önünde tutarak önümüzdeki yıllarda yazılacak tezler ve yapılacak akademik çalışmaların sayıca artacağı öngörülmektedir. Çalışmamızın mevcut çalışmaların içeriğinin topluca değerlendirilmesi ve eksik alanları işaret etmesi açısından alan yazına katkı sağlayacağı düşünülmektedir.

\section{KAYNAKÇA}

Afonso, A.M., Cadwell, J.B. (2021). Burnout rate and risk factors among anesthesiologists in the United States, Anesthesiology, 134(5), 683-696.

Akkoç, İ., Okun, O., Türe, A. (2020). The effect of role-related stressors on nurses' burnout syndrome: the mediating role of work-related stress, Perspectives in Psychiatric Care, $1-14$. 
Bauer, J., Hafner, S., Kachele, H., Wirsching, M., \& Dahlbender, R.W. (2013). The burnout syndrome and restoring mental health at the working place, psychotherapie: Pyschosomatik, Medizinische Psychologie, 53(5), 213-222.

Bayram, M., \& Yaylı, A. (2009). Otel web sitelerinin içerik analizi yöntemiyle değerlendirilmesi, Elektronik Sosyal Bilimler Dergisi, 8(27), 347-379.

Bianchi, R., Schonfeld, I.S., Laurent, E. (2015). Is it time to consider the "burnout syndrome" a distinct illness?, Frontiers in Public Health, (3), 1-3.

Bridgeman, P.J., Bridgeman, M.B., Barone, J., (2017). Burnout syndrome among healthcare professionals, American Journal of Health-System Pharmacy, (74), 576-581.

Carod-Artal, F.J., Vazquez-Cabrera, C. (2013). Burnout syndrome in an international setting. In: Bahrer-Kohler, S. (Eds.) Burnout For Exports (s. 15-35). Springer.

Chirico, F., Crescenzo, P., Sacco, A., Ricco, M., Ripa, S., Nucera, G., Magnavita, N. (2021). Prevalence of burnout syndrome among italians volunteers of the red-cross: a crosssectional study. Industrial Health, 59, 117-127.

Elo, S., Kyngas, H. (2007). The qualitative content analysis process, Journal of Advanced Nursing, May 2008, 107-115.

Freudenberger, H. J. (1975). The staff burnout syndrome in alternative institutions. psychotherapy: Theory, Research and Practice, 12(1), 73-82.

Embriaco, N., Papazian, L., Kentish-Barnes, N., Ponchard, F., \& Azoulay, E. (2007). Burnout syndrome among critical care healtcare workers. Current Opinion in Critical Care, (13), 482-488.

Gil-Calderon, J., Alonso-Molero, J., Dierssen-Sotos, T., Gomez-Acabo, I., \& Llorca, J. (2021). Burnout syndrome in Spanish medical students, BMC Medical Education, (21), 231, 17. 
Leitao, J., Pereira, D., \& Gonçalves, A. (2021). Quality of work life and contribution to productivity: assessing the moderator effects of burnout syndrome, International Journal of Environmental Research and Public Health, 18(2425), 1-20.

Leiter, M. P. (1992). Burnout as a crisis in self-efficacy: Conceptual and practical implications, Work \& Stress, 6(2), 107-115.

Magnavita, N., Chirico, F., Garbarino, S., Braggazi, N. L., Santacroe, E., \& Zaffina, S. (2021). SARS/MERS/SARS COV-2 Outbreaks and burnout syndrome among healthcare workers. An umbrella systematic review, International Journal of Environmental Research and Public Health, (18), 4361. doi: 10.3390/ijerph18084361

Maslach, C., \& Pines, A. (1977). The burn-out syndrome in the day care setting, Child-Care Quarterly, 6(2), 100-113.

Montero-Marin, J., Garcia-Campaye, J., Mosquera Mera, D., \& Lopez del Hoyo, Y. (2009). A new definition of burnout syndrome based on farber's proposal, Journal of Occupational Medicine and Toxicology, 4(31), 1-17.

Poncet, M.C., Toullic, P., Papazian, L., Kentish-Barnes, N., Timsit, J., Pochard, F., Chevret, S., Sclemmer, B., \& Azoulay, E. (2007). Burn out syndrome in critical care nursing staff. American Journal of Respiratory and Critical Care Medicine, 175(2007), 698704.

Rodrigues, H., Cobucci, R., Oliveira, A., Cabral, J.V., Medeiros, L., Gurgel, K., Souza, T., \& Gonçalves, A.K. (2018). Burnout syndrome among medical residents: a systematic review and meta analysis. PLoS ONE, 13 (11), 1-17.

Weber, A., \& Jaekel-Reinhard, A. (2000). Burn-out syndrome: A disease of modern societies?, Occupational Medicine, 50 (7), 512-517.

Yükseköğretim Kurumu (2021). www.tez.yok.gov.tr/UlusalTezMerkezi/, Erişim Tarihi: 10.08.2021. 